\title{
AGREEMENT BETWEEN ORAL CONTRACEPTIVE USERS AND PRESCRIBERS: IMPLICATIONS FOR CASE-CONTROL STUDIES
}

\author{
F.E. van Leeuwen ${ }^{*}$, C.M. van Duijn ${ }^{\S}$, M.H.T.H. Camps*, B.A.M. Kempers ${ }^{\S}$, \\ M.F.M.H.Mentjens ${ }^{\xi}$ ' H.B. Mulder", E.G. Schouten\$, R.M.L. Zwijsen ${ }^{\xi}$, M.A. Rookus \\ * From the Department of Epidemiology, The Netherlands Cancer Institute, Amsterdam, \\ The Netherlands \\ $\$$ Agricultural University, Department of Epidemiology and Public Health, Wageningen, \\ The Netherlands
}

\begin{abstract}
Case-control studies examining the effects of oral contraceptives (OC) are prone to misclassification bias due to errors in assessment of $O C$ use. Concern about inaccurate exposure histories has increased since current studies require women to recall $O C$ use over prolonged periods of time. In preparation for a case-control study of breast cancer and OC use, an investigation was carried out to assess agreement between women's lifetime histories of OC use (covering a period of up to 20 years) and prescribers' records. OC histories were obtained during personal intervlew with 218 women who had used OC at some point in their lives (127 breast cancer patients, 91 controls). Recall was aided by an album with color photographs of all OC marketed in the Netherlands from 1962 onwards $(n=65)$, and a calendar that covered the women's life span from date of birth to menopause. The participants were asked for the names of all physicians who prescribed $O C$ for them. The rate of response from the prescribers was high $(94 \%)$, but only half of the forms provided useful information. Patient-prescriber agreement on brand names (including dosage) was $70 \%$. About half of the women agreed with their prescribers on starting dates to within less than a year's difference. Approximately the same percentage of agreement was found for stopping dates. Multiple linear regression indicated that agreement on brand names and dates of usage was lower for women of low socioeconomic status, for healthy women (as compared to breast cancer patients) and for periods of pill use that had to be recalled from the more distant past. Agreement on total duration of use was high enough to permit testing of a moderately strong duration-response relationship in a case-control study.
\end{abstract}

\section{Introduction}

No epidemiologic study can be better than the quality of the raw data collected for analysis $(1,2)$. Although this well-known statement is regarded as a generally accepted truth, it often tends to be forgotten in epidemiologic practice. This certainly holds true for case-control studies examining the effects of oral contraceptive (OC) use on breast cancer risk. Since the 1960's, when OC came into widespread use, more than 30 such studies have been conducted of which all except one (3) relied totally on the memory of the woman for information about OC use. In more recent case-control studies, women had to recall OC use, including brand names, starting and stopping dates of each contraceptive pill taken, over a period of twenty years or more. Skegg reviewed the potential biases in the studies of breast cancer and OC conducted to date and, among others, expressed concern about bias arising from misclassification of exposure (4). In the absence of information on OC use from an independent source (e.g., physician records), inaccuracy of OC histories from the women may lead to differential and/or undifferential misclassification. Non-differential misclassification, mostly resulting in a reduced ("diluted") relative risk estimate, is inevitable in any study using subjects' information only $(5,6)$. Differential misclassification may affect the relative risk estimate upward if breast cancer cases, by looking for the possible causes of their disease, overestimate their duration of $O C$ use as compared to controls (4). Although the separate and combined effects of differential and non-differential misclassification have not been assessed in any of the studies of OC use and breast cancer, other investigations addressed this issue. In several studies (7-10), a

Correspondence to :

Flora E. van Leeuwen

Department of Epidemiology

The Netherlands Cancer Institute

121 Plesmanlaan,

1066 CX Amsterdam, The Netherlands

Submitted for pub1ication January 14, 1992

Accepted for publication March 23, 1992 
comparison of women's contraceptive histories with physicians' records was made. Unfortunately, these studies are of only limited value to the current discussion. Three of these studies (7-9) were conducted in the mid-seventies, and thus could not yield information about recall of prolonged periods of $O C$ use. Two studies $(7,10)$ were restricted to healthy women, thus rendering it impossible to assess differential misclassification. A recent case-control study in the UK examined specifically differential misclassification of duration of OC use. Such misclassification was found to be negligible (3).

In the present study, we report on the extent of agreement between women's recalled OC use and prescribers' records. The study population consists of breast cancer cases and controls who participated in a pilot study to test data collection procedures for a case-control study of breast cancer and $O C$ use in The Netherlands. From the comparison between $O C$ histories of users and prescribers, we calculated the extent of misclassification bias to be expected in a case-control study. In addition, we examined which characteristics of the women affected levels of agreement.

\section{Methods}

\section{Study Pooulation}

The present study was not part of a case-control study of breast cancer and OC use, but specificaily addressed the feasibility and validity of data collection procedures for such a study. Therefore, eligibility criteria for cases and controls were chosen primarily on practical grounds and differed from the criteria employed in the actual case-control study. The study population consisted of 151 breast cancer cases and 93 healthy controls. Cases were diagnosed with breast cancer in the Netherlands Cancer Institute (Antoni van Leeuwenhoek Hospital) between January 1980 and November 1985, who reported OC use for more than one month at some point in their lives and who were under 65 years of age. Interviews took place during the period January 1983 - January 1986. For $75 \%$ of the cases, the interview took place within a year of diagnosis. Two control groups were used: friend controls $(n=60)$ and hospital controls with a diagnosis of benign breast disease 5 years or more before time of interview $(n=33)$. Like the cases, controls had some reported history of OC use and were younger than 65 years.

Breast cancer cases and hospital controls were asked to participate in the study via an explanatory letter signed by their treating physician. Friend controls were selected by asking 60 breast cancer patients for the name of a friend who had ever used the pill, who was about their age and who would be willing to participate. All women were told that the purpose of the study was to assess the accuracy of recalling prescribed drug use.

\section{Data Collection}

Information on OC use was collected via personal interviews conducted by six trained, female interviewers. Interviews took 30 minutes to 1 hour to complete. To help women in recalling the specific brand names and the starting and stopping dates of each contraceptive pill ever taken, two memory aids were used. First, an album was prepared with color photographs of all OC (both packages and pills) ever marketed in The Netherlands from 1962 onwards (65 preparations). Next to each photograph was indicated the period during which the preparation had been on the market. Second, a calendar was used that covered a woman's life span from date of birth to menopause. All reproductive and other life events that were considered to be helpful in recalling OC use were noted on this calendar.

Women were asked for the names of all physicians and health care facilities that had prescribed their OC. All prescribers were sent an explanatory letter about the purpose of the study. A standard form was enclosed (with a stamped, self-addressed envelope), that requested prescribers to fill out specific brand names and starting and stopping dates of all OC preparations used by the women concerned. Also enclosed was a form, signed by the woman, in which she gave us permission to ask prescribers for information about her OC use. Prescribers who did not respond initially were followed up with a maximum of two telephone contacts.

\section{Data Analysis}

Agreement of each woman's history of OC use with that provided by her prescriber(s) was calculated for the following aspects of OC use: specific brand name (including dose), starting date, stopping date and duration of use. This was done for all OC combined and, separately, for the first, the latest and the second-latest $O C$ used. For women who used only one type of OC, this was regarded as her first and her latest $O C$. A secornd-latest $O C$ was assumed only to exist for women who used more than two pills. Total duration of use was calculated by summing up the time periods between stopping date and starting date of each preparation used. Extent of user/prescriber agreement regarding types of OC use (e.g. first used vs. last used) and subgroups of women were 
tested for statistical significance with the chi-square test. Chance agreement was not corrected for since the number of OC preparations on the market was high $(n=65)$ and also varied by time period.

Multiple linear regression analysis was carried out to examine whether agreement could be explained by characteristics of the women and by calendar period of OC use. The dependent variable in this analysis was dichotomous for agreement on brand name (agreement vs. no agreement), and was defined as the difference in months between user and prescriber for agreement on dates of usage. Given the dichotomous nature of the dependent variable for agreement on brand name, this analysis was also done employing discriminant function analysis. The two analytic approaches yielded equivalent results. In the present report only results emanating from the multiple linear regression analysis will be shown.

The effect of misclassifications in duration of use on the relative risk estimates in a hypothetical case-control study was calculated according to Marshall et al. (6). For this calculation it is necessary to assume that: a) prescribers' records are more valid than OC histories as recalled by the women themselves; and b) a duration-response relationship exists between $O C$ use and breast cancer risk.

\section{Results}

\section{Study Population}

Of a total of 151 breast cancer patients and 93 controls contacted, 134 cases (89\%) and 91 controls $(98 \%)$ agreed to participate. The non-responders among the cases were all, except one, stage III and IV patients, who were already in a terminal phase of disease when approached for the interview. Seven interviews with cases could not be used for various reasons, such as lack of permission to contact the prescriber (2 cases), being one's own prescriber (2 cases) and having contact with prescribers about $O C$ use after having been asked to participate in the study ( 3 cases). Thus, we were able to approach the prescribers of 218 women (127 cases and 91 controls). Table I presents several characteristics of the study population.

The median duration of $O C$ use amounted to 8.1 years and one-third of the study population had started $O C$ use more than 20 years before the interview. No significant differences were present between breast cancer patients and controls with respect to age distribution and characteristics of OC use. The median age of cases and controls was 46.2 and 44.7 years, respectively $(p=0.46)$.

\section{Table I}

Characteristics of women and their $O C$ use in the study population $(n=218)$

\begin{tabular}{|c|c|c|c|}
\hline Characteristic & $\%$ of population & Characteristic & popule \\
\hline Study group & & Starting date & \\
\hline Cases & 58.3 & before July 1965 & 33.1 \\
\hline Controls & 41.7 & $\begin{array}{l}\text { July ' } 65 \text { - July ' } 70 \\
\text { July } 70 \text { - July ' } 75\end{array}$ & $\begin{array}{l}42.2 \\
20.1\end{array}$ \\
\hline Age at interview & & after July ' 75 & 4.6 \\
\hline$\leq 30$ & 4.7 & & \\
\hline$\overline{31}-40$ & 21.9 & Stopping date & \\
\hline $41-45$ & 21.4 & before July 1973 & 24.2 \\
\hline $46-50$ & 26.0 & July '73 - July '81 & 46.8 \\
\hline $51-60$ & 22.3 & after July ' 81 ' & 23.7 \\
\hline $61-65$ & 3.7 & still user in $1984 / 85$ & 5.3 \\
\hline Number of prep & used & Total duration of use & \\
\hline 1 & 30.0 & $0-2$ years & 22.8 \\
\hline 2 & 36.4 & 2 - 6 years & 21.6 \\
\hline 3 & 21.7 & $6-10$ years & 27.8 \\
\hline$\geq 4$ & 11.9 & $\begin{array}{l}10-12 \text { years } \\
>12 \text { years }\end{array}$ & $\begin{array}{l}12.2 \\
15.6\end{array}$ \\
\hline
\end{tabular}

\section{Prescriber's response}

The study population of 218 women reported a total of 598 periods of OC use. Prescriber response amounted to $93.6 \%$, but the amount of information supplied varied substantially. Information on either brand name or date(s) of usage became available for only $46.1 \%$ of the periods of $O C$ use mentioned by the women. Only for $33.6 \%$ of the recalled OC periods was 
prescriber information complete, i.e. both the specific brand name, starting date and stopping date were mentioned. The main reason for unavailability of prescriber information was retirement or death of the actual prescriber. In such cases, data on the patient's OC use had not been forwarded onto the woman's new physician. As a consequence, prescriber availability of OC information was lower for preparations first used than for preparations last used $(24.8 \%$ vs $42.7 \%)$. Prescriber response did not vary significantly by case-control status or age group.

\section{Agreement on brand names}

Table II displays data on agreement between users and prescribers on formulation-specific brand names. For all women combined, agreement was higher (though not significantly so) for the latest $O C$ used than for OCs used previously. When cases and controls were considered separately, however, agreement did not vary by sequence of use for the patients, whereas for the controls, agreement was lower for first and second-latest pill than for the most recent plll used $(p<0.10)$. Breast cancer patients showed higher agreement on brand names than controls, though the difference was not statistically significant $(74 \%$ and $65 \%$ respectively; $p=0.17)$.

\section{Table II}

Agreement of OC users with prescribers on specific brand name, by order of pill use and case/control status (in parentheses the number of $\mathrm{OC} s$ for which agreement could be calculated)
OC characteristic
$\%$ agreement

\begin{tabular}{lllllll} 
& \multicolumn{2}{c}{ cases } & \multicolumn{2}{c}{ Controls } & \multicolumn{2}{c}{ total } \\
\cline { 5 - 7 } most recent OC used & 75.0 & $(n=68)$ & 72.7 & $(n=33)$ & 74.3 & $(n=101)$ \\
second-latest OC used & 76.5 & $(n=34)$ & 50.0 & $(n=14)$ & 68.8 & $(n=48)$ \\
first OC used & 74.5 & $(n=55)$ & 58.3 & $(n=24)$ & $69.6 \quad(n=79)$ \\
all OC used & 73.5 & $(n=155)$ & 64.9 & $(n=77)$ & $70.7 \quad(n=232)$
\end{tabular}

\section{Agreement on dates of usage}

Table III shows agreement between users and prescribers on starting and stopping dates. This table provides the cumulative percentages of agreement when agreement is defined as a difference of less than $x$ months in dates as reported by $O C$ user and prescriber (with $x$ varying between 6 and 48 ). For example, $38.2 \%$ of OC users recalled a starting date of their first OC that was less than 6 months apart from the date recorded by the prescriber.

\section{Table III}

Agreement of $O C$ users with prescribers on starting and stopping dates of the first and the most recent $O C$ used

\section{Cumulative $\%$ agreement}

\begin{tabular}{|c|c|c|c|c|c|c|}
\hline \multirow{2}{*}{$\begin{array}{l}\text { Agreement, defined } \\
\text { as a user-prescriber } \\
\text { difference } \\
\text { of }\end{array}$} & \multicolumn{3}{|c|}{ Starting dates of } & \multicolumn{3}{|c|}{ Stopping dates of } \\
\hline & $\begin{array}{l}\text { first } \\
\text { OC } \\
(n=68)\end{array}$ & $\begin{array}{l}\text { most } \\
\text { recent } \\
\text { OC } \\
(n=82)\end{array}$ & $\begin{array}{l}\text { all } \\
\text { OC } \\
(n=183)\end{array}$ & $\begin{array}{l}\text { first } \\
\text { OC } \\
(n=54)\end{array}$ & $\begin{array}{l}\text { most } \\
\text { recent } \\
\text { OC } \\
(n=89)\end{array}$ & $\begin{array}{l}\text { all } \\
\text { OC } \\
(n=179)\end{array}$ \\
\hline$\leq 6$ months & 38.2 & 33.0 & 34.4 & 42.6 & 41.7 & 43.6 \\
\hline$\leq 12$ months & 52.9 & 48.9 & 47.0 & 48.2 & 62.9 & 53.7 \\
\hline$\leq 24$ months & 72.0 & 66.0 & 65.6 & 74.1 & 80.9 & 74.3 \\
\hline$\leq 48$ months & 85.2 & 84.3 & 85.3 & 88.9 & 95.5 & 91.0 \\
\hline$>48$ months & 100.0 & 100.0 & 100.0 & 100.0 & 100.0 & 100.0 \\
\hline
\end{tabular}


Agreement on the starting date of the first $\mathrm{OC}$ used was slightly higher as compared with that for all other OC combined $(p=0.52)$. For stopping dates (Table III), agreement on the latest $O C$ used showed higher agreement than that on other $O C$ preparations $(p=0.09)$. Agreement on stopping date of the second-latest OC used showed a distribution similar to that of the first OC used (not shown). For a study of breast cancer and OC,we considered a user-prescriber difference of less than 12 months as acceptable. In general, about $50 \%$ of the women matched their prescriber within such a margin; only for the stopping date of the latest $O C$ used was agreement over $60 \%$. Breast cancer patients and controls showed very similar distributions for agreement on starting and stopping dates both of the first and the latest $O C$ used (all p-values exceeding 0.80 ; not shown).

\section{Agreament on duration of use}

Agreement on total duration of use could be calculated only in those cases where we were able to obtain information from both user and prescriber on dates of usage of all OC used by one woman. This was achleved for only 44 women (33 cases and 11 controls). Agreement on total duration to within 2 years, which we considered to be acceptable in an actual case-control study. was $59.1 \%$. This percentage did not differ significantly between breast cancer patients and controls ( $60.6 \%$ and $54.6 \%$, respectively).

Since the effect of different brands of $O C$ on risk of disease may vary, duration of use per preparation is also a useful measure in epidemiologic studies. Agreement on preparation-specific duration of use could be calculated for a much larger sample than total duration of use. As is shown in Table IV, about half of the women agreed with their prescribers to within one year. The percentage agreement for cases was sllghtly higher than for controls, but the difference was not statistically significant $(p=0.34)$.

\section{Table IV}

Agreement of $\mathrm{OC}$ users with prescribers on preparation-specific duration of use, by case-control status

\begin{tabular}{llll}
$\begin{array}{l}\text { Agreement } \\
\text { defined as a } \\
\text { user-prescriber } \\
\text { difference } \\
\text { of }\end{array}$ & \multicolumn{3}{c}{ Cumulative \% agreement } \\
\hline$\leq 6$ months & 38.1 & 27.1 & 34.6 \\
$(n=105)$ & $\begin{array}{l}\text { controls } \\
(n=48)\end{array}$ & $\begin{array}{l}\text { total } \\
(n=153)\end{array}$ \\
$\leq 12$ months & 56.2 & 39.6 & 51.0 \\
$\leq 24$ months & 70.5 & 64.6 & 68.5 \\
$\leq 48$ months & 87.6 & 87.5 & 87.5 \\
$>48$ months & 100.0 & 100.0 & 100.0
\end{tabular}

In Table $V$ we calculated the apparent relative risk estimates for a hypothetical case-control study exhibiting the same degree of misclassification in total duration of use as was found in the present study. As can be seen in the upper part of Table $V$ the actual relative risk gradient in the hypothetical study is assumed to result from increasing duration of exposure among cases and a uniform level among controls. From the lower part of Table V, it can be seen that the apparent relative risk gradient, though less steep than the actual one, is clearly emerging. This is due to the fact that breast cancer patients and controls were about equally likely to overstate or understate their exposure. For both cases and controls, overstatement occurred much more frequently than understatement. We repeated the same calculations for the duration of the longest OC used since this information was avallable for many more women $(n=74)$ and also showed sufficient variation. Here the apparent relatlve risk gradient differed even less from the actual one than was the case for total duration of use. It must be noted, however, that the degree of misclassification found in our study might easily obliterate a much weaker duration-response relationship than the one hypothesized in Table V (e.g., an "actual" relative risk of 2.0 instead of 6.0 associated with the longest duration of actual $O C$ exposure). 


\section{Table V}

The effect of misclassification of duration of $O C$ use in a hypothetical case-control study with $21 \mathrm{~A}^{\S}$ cases and $6 C^{\$}$ controls and a duration-response gradient with increasing exposure

\section{Actual situation}

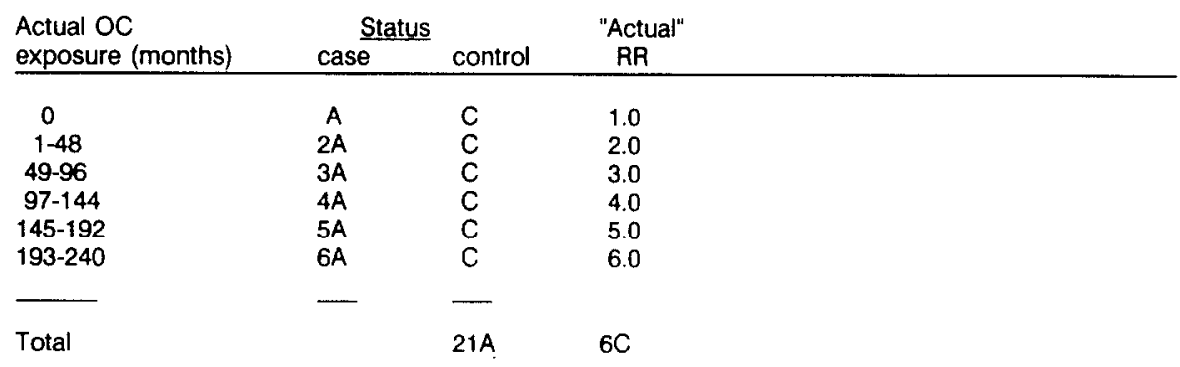

Observed situation

Reported OC exposure (months) cases controls

\section{"Apparent" "Apparent"}

RR for total duration of use +
RR for duration

of the longest

OC used\#

\begin{tabular}{llcll}
\hline & $(1-p) A+2 q A$ & & \\
0 & $2(1-p-q) A+p A+3 q A$ & $(1-p) C+q C$ & 1.0 & 1.0 \\
$1-48$ & $3(1-p-q) A+2 p A+4 q A$ & $C$ & 1.4 & 1.8 \\
$49-96$ & $4(1-p-q) A+3 p A+5 q A$ & $C$ & 2.2 & 2.7 \\
$97-144$ & $5(1-p-q) A+4 p A+6 q A$ & $C$ & 2.7 & 3.7 \\
$145-192$ & $6(1-q) A+5 p A$ & $C$ & 3.4 & 4.7 \\
$193-240$ & $(1-q) C+p C$ & 4.4 & 5.9 \\
\hline
\end{tabular}

$\mathrm{RR}=$ relative risk estimated as odds ratio

$\$ A=$ number of cases and $C=$ number of controls, who were actually not exposed to $O C$

* Calculations according to Marshall et al (6)

$p=$ proportion of subjects whose exposure is overstated

$q$ = proportion of subjects whose exposure is understated

$+p$ cases $=0.36, p$ controls $=0.44$, $q$ cases $=0.09, q$ controls $=0.09$

\# $p$ cases $=0.29, p$ controls $=0.22, q$ cases $=0.06$, $q$ controls $=0.04$

\section{Factors affecting aoreement}

In Table VI results are reported of a multiple linear regression analysis in which the potential effects of age, socioeconomic status and case-control status on agreement levels were examined. Besides these user characteristics, we also investigated recall period (i.e. period over which a woman has to recall her OC use) and the sequence of use (l.e. Whether a specific preparation was used as the first or latest $O C$, or in between).

An interesting finding is that women of medium and high socioeconomic status agreed better with prescribers on both brand names and dates of usage than women of low socioeconomic status. A woman's age and her case-control status did not significantly affect agreement, although cases tended to show higher agreement on brand names than controls. Further, the recall period was found to affect agreement on stopping dates and brand names. Agreement was significantly less when the period of pill use was in the more distant past. With recall period taken into account, there was little difference in agreement between the first and the latest $O C$ used. A general tendency was noted for intermediate pilis to show less agreement than first or latest used preparations.

Because of concern for the non-independence of agreement on usage of different OC's taken by the same woman, the analyses were run separately for women who used one pill only. Again, recall period and socioeconomic class clearly emerged as significant elfects. 


\section{Table V}

Multiple regression models with agreement on brand names, starting dates and stopping dates as dependent variables

\begin{tabular}{|c|c|c|c|c|c|c|}
\hline Variable & $\begin{array}{l}\text { Agreement on } \\
\text { brand names } \\
(n=178)\end{array}$ & & $\begin{array}{l}\text { Agreement on } \\
\text { starting } \\
\text { dates }(n=189)\end{array}$ & & $\begin{array}{l}\text { Agreement on } \\
\text { stopping } \\
\text { dates }(n=179)\end{array}$ & \\
\hline & $B \pm S E * *$ & $p$ value & $B^{*} \pm S E^{* \star}$ & $p$ value & $B^{*} \pm S E^{* *}$ & $p$ value \\
\hline Intercept & 0.54 & & 7.82 & & 51.2 & \\
\hline Recall period \#** & $\begin{array}{l}-1.23 .10^{-3} \\
\pm 6.70 .10^{-4}\end{array}$ & 0.07 & $-0.03 \pm 0.05$ & 0.51 & $-0.11 \pm 0.03$ & 0.0015 \\
\hline \multicolumn{7}{|l|}{ OC sequence+ } \\
\hline $\begin{array}{l}\text { - latest } \\
\text { - intermediate }\end{array}$ & $\begin{array}{l}0.03 \pm 0.10 \\
0.15 \pm 0.10\end{array}$ & $\begin{array}{l}0.74 \\
0.16\end{array}$ & $\begin{array}{r}5.24 \pm 6.09 \\
11.70 \pm 6.10\end{array}$ & $\begin{array}{l}0.39 \\
0.06\end{array}$ & $\begin{array}{r}-3.21 \pm 5.43 \\
5.78 \pm 5.41\end{array}$ & $\begin{array}{l}0.56 \\
0.29\end{array}$ \\
\hline \multicolumn{7}{|l|}{$\begin{array}{l}\text { Socloeconomic } \\
\text { status }++\end{array}$} \\
\hline $\begin{array}{l}\text { - medium } \\
\text { - high }\end{array}$ & $\begin{array}{r}0.03 \pm 0.08 \\
-0.16 \pm 0.09\end{array}$ & $\begin{array}{l}0.66 \\
0.09\end{array}$ & $\begin{array}{l}-10.06 \pm 5.11 \\
-11.34 \pm 5.91\end{array}$ & $\begin{array}{l}0.05 \\
0.06\end{array}$ & $\begin{array}{l}-7.01 \pm 5.41 \\
-8.58 \pm 4.78\end{array}$ & $\begin{array}{l}0.09 \\
0.07\end{array}$ \\
\hline $\begin{array}{l}\text { Case-control } \\
\text { status }+++\end{array}$ & $-0.08 \pm 0.07$ & 0.25 & $2.91 \pm 4.60$ & 0.53 & $-1.87 \pm 3.81$ & 0.62 \\
\hline Age & $\begin{array}{l}5.9 .10^{-4} \pm 4.7 .10^{-3} \\
R^{2}=0.08\end{array}$ & 0.92 & $\begin{array}{l}0.43 \pm 0.32 \\
\mathrm{~A}^{2}=0.09\end{array}$ & 0.18 & $\begin{array}{l}-0,07 \pm 0.25 \\
R^{2}=0.14\end{array}$ & 0.77 \\
\hline
\end{tabular}

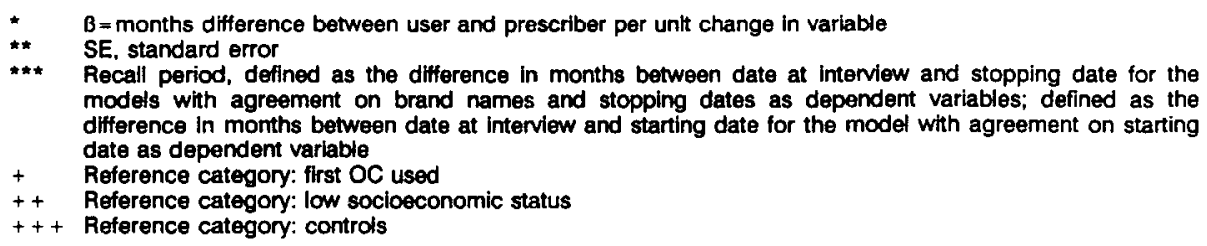

\section{Discussion}

A major problem in validity studies on women's recall of OC use is that the absolute truth is unknown. Accuracy of recall is generally measured through agreement between the women's recalled $O C$ use and prescriber records. This is an imperfect approach for several reasons. Firstly, not one study, this one included, checked prescriber records for women who reported no history of $O C$ use. Although $O C$ use is not likely to be forgotten by a woman, it cannot be ruled out that some women may be unwilling to report a history of very early $O C$ use. Secondly, prescribers may be a less reliable source of information on dates of usage, as it is not uncommon for women to stop OC use without notifying their physician. Thirdly, prescriber records are often incomplete and, as a consequence, agreement can only be calculated for a subset of women. However, we do not believe that this is likely to lead to bias in studies like ours where missing prescriber information is not due to lack of prescriber collaboration, but to (partial) destruction of archives which often accompanies a prescriber's retirement or death. Fourthly, it is quite common that current prescribers do not have all earlier OC use at their disposal. Therefore, we contacted all prescribers mentioned by each woman. This approach entails the danger that a woman forgets an early prescriber or thinks that her early $O C$ use was prescribed for her by a later prescriber. In such cases, the proportion of agreement reported 
in the present study is too low. Rosenberg et al. mention a fifth source of potential bias, namely, the exclusion from analysis of women who could not remember the names of their prescribers (9). Bias would arise if such women were also less likely to remember their OC use. In our study, apparently, no women had to be excluded for this reason (i.e., for all preparations recalled, all women could recollect the names of the relevant prescribers). It is still possible, however, that some women failed to remember a prescriber because they did not recall the use of the preparation he/she had prescribed. Finally, comparing the women's OC history with prescriber records implies that in all validity studies, permission has be sought from the women to approach their prescriber(s). Awareness of the fact that $O C$ information will be checked with prescriber information may bring the women to more extensive memory searching. Hence, the accuracy of a woman's OC information as assessed in validity studies may have been affected upwardly as compared to studies in which OC information is collected solely from the women.

With the above limitations in mind, it is clear that the results reported here should not be interpreted as the absolute validity of OC histories obtained by interview. Rather, we should speak of the relative validity of recalled OC use, with prescriber records as the only available, but imperfect, standard for measuring validity. Since computerized prescription forms from pharmacies have oniy become avallable in The Netherlands in the last few years, this information could not be used as a source of comparison with women's recalled life-time OC use.

Table VII lists the results of all OC agreement studies conducted to date. A comparison between our results and those of previous studies is difficult, however, because of differences in study populations and methods. Since the agreement studies in the 1970's were carried out (7-9), the number of OC preparations on the market has increased and, even more importantly, the interval between first OC use and interview has been substantially extended. Also, our population is considerably older than that in all other studies. Further, two early studies did not yet employ memory aids such as a book of OC photographs and a life events calendar $(7,8)$.

As might be expected from the above considerations, agreement in our study tended to be lower than reported in most previous studies (Table VII). However, agreement on formulation-specific brand name was certainly not lower than in earlier studies when taking into account that Glass et al. and Stolley et al. did not require agreement on dosage $(7,8)$.

Also when compared to the recent study by Coulter et al. (10), agreement on dates of usage and duration of use seems rather low in the present study. For example, $69 \%$ of women interviewed with memory aids in the former study, showed agreement on total duration of use to within one year, whereas this was only $47 \%$ in our study. Higher agreement in the Coulter study may be explained by the fact that a different source of comparison was used. The women were participants of the prospective cohort study of the Oxford-Family Planning Association and their recalled histories were compared with self-reported histories of actual use as recorded annually during the course of the study. The advantage of this approach is that the study did not rely on prescriber's records of sometimes questionable quality. Particularty for stopping dates and, as a consequence, aiso for the duration of use, prescribers may be inaccurate and this would tend to produce lower agreement in all studies using prescriber records as compared to Coulter's study. However, there are also some disadvantages to Coulter's source of comparison: a) the study population was so used to answering questions about its $O C$ use that a certain training effect may have taken place, and b) the source of comparison for very early OC use was probably also women's recall, i.e. when they entered the cohort at age 25. Both of these disadvantages would also tend to elevate the observed proportion of agreement in Coulter's study.

We examined the impact of our rather low agreement on duration of use by computing the effect of misclassifications on relative risk estimates in a hypothetical case-control study. Despite considerable overstatement of total duration of use by OC users, a woman's recall was found to be accurate enough to examine the presence of a moderately strong duration-response relationship. A weak duration-response relationship might be masked by the degree of misclassification in our study. An important finding is that misclassification of duration was mainly non-differential in our data. A negligible degree of differential misclassification was also found in the only other case-control study of breast cancer and OC that examined its effect (3). In that study, which was restricted to women under age 36 , it was calculated that, at most, cases remembered $2 \%$ more of their actual oC use than did controls. The extent of non-differential misclassification was not reported, probably because of the high degree of incompleteness of prescribers' records. It was found that both cases and controls reported approximately double the use recorded in prescribers' notes, thus calling into question the value of information from prescribers as a validity standard (3). In line with these results, Rosenberg et al. did not observe a significant difference between cases of hepatocellular adenoma and controls in agreement on total duration of $O C$ use (9). In contrast, Stolley et al. reported significantly better agreement on starting date of last $O C$ and duration of use for cases with thromboembolic disease as compared to controls. As in our study, Stolley et al. reported that overstatement of duration was more common than understatement, but, surprisingly, controls tended 
Iable VI Summary of studies of agreement on OC histories between users and prescribers

\begin{tabular}{|c|c|c|c|c|c|}
\hline & & Firsta & or (vear of publl & tion) & \\
\hline Characteristic & $\begin{array}{l}\text { Glass } \\
(1974) \\
\end{array}$ & $\begin{array}{l}\text { Stolley } \\
(1978)\end{array}$ & $\begin{array}{l}\text { Rosenberg } \\
\text { (1983) }\end{array}$ & $\begin{array}{l}\text { Coulter } \\
(1986)\end{array}$ & $\begin{array}{l}\text { Van Leeuwen } \\
\text { (1991) }\end{array}$ \\
\hline Study population & $\begin{array}{l}75 \text { healthy } \\
\text { women }\end{array}$ & $\begin{array}{l}79 \text { cases of } \\
\text { thrombo- } \\
\text { embolism, } \\
197 \text { hospltal } \\
\text { controls }\end{array}$ & $\begin{array}{l}61 \text { cases of } \\
\text { hepatocellular } \\
\text { adenoma } \\
69 \text { healthy }\end{array}$ & $\begin{array}{l}99 \text { healthy } \\
\text { women }\end{array}$ & $\begin{array}{l}127 \text { breast cancer cases } \\
58 \text { healthy controls } \\
33 \text { hospital controls }\end{array}$ \\
\hline Age & $\begin{array}{l}60 \% \\
<35 \text { yrs }\end{array}$ & $\begin{array}{l}<50 \text { yrs } \\
(80 \%<35)\end{array}$ & $71 \%<35$ yrs & $35-41$ yrs & $\begin{array}{l}<65 \text { yrs } \\
(12 \%<35 \text { yrs })\end{array}$ \\
\hline Year of study & $?$ & $1970-1973$ & 1976 & 1984 & $1983-1985$ \\
\hline Aareement & & & & & \\
\hline $\begin{array}{l}\text { Brand name } \\
\text { latest OC }\end{array}$ & $79 \%$ & $89 \% *$ & n.r. & $53-63 \%$ & $74 \%$ \\
\hline $\begin{array}{l}\text { Brand name } \\
\text { first } O C\end{array}$ & $74 \% *$ & n.r. & n.r. & $69 \%$ & $70 \%$ \\
\hline $\begin{array}{l}\text { Starting date } \\
\text { first OC }\end{array}$ & n.r. & n.r. & n.r. & $\begin{array}{l}90 \% \\
( \pm 1 \text { year })\end{array}$ & $\begin{array}{l}53 \% \\
( \pm 1 \text { year })\end{array}$ \\
\hline $\begin{array}{l}\text { Starting date } \\
\text { latest OC }\end{array}$ & n.r. & $\begin{array}{l}52 \% \\
( \pm 1 \text { month) }\end{array}$ & n.r. & n.r. & $\begin{array}{l}49 \% \\
( \pm 1 \text { year })\end{array}$ \\
\hline $\begin{array}{l}\text { Stopping date } \\
\text { latest OC }\end{array}$ & n.r. & $\begin{array}{l}74 \% \\
\text { ( } \pm 1 \text { month) }\end{array}$ & n.r. & $\begin{array}{l}63-79 \% \\
( \pm 1 \text { year })\end{array}$ & $\begin{array}{l}63 \% \\
( \pm 1 \text { year })\end{array}$ \\
\hline Total duration & $80-90 \% \star \star \star$ & $\begin{array}{l}36 \% \\
( \pm 1 \text { month })\end{array}$ & $\begin{array}{l}90 \% \text { * } \\
( \pm 1 \text { month) }\end{array}$ & $\begin{array}{l}57-69 \% \\
( \pm 1 \text { year })\end{array}$ & $\begin{array}{l}47 \% \\
( \pm 1 \text { year })\end{array}$ \\
\hline & & $\begin{array}{l}77 \% \\
( \pm 1 \text { year })\end{array}$ & & $\begin{array}{l}77 \%-94 \% \\
( \pm 2 \text { years) }\end{array}$ & $\begin{array}{l}59 \% \\
\text { ( } \pm 2 \text { years) }\end{array}$ \\
\hline
\end{tabular}

$\begin{array}{ll}\text { n.r. } & \text { not reported } \\ * & \text { For agreement on brand name,agreement on correct dosage was not required } \\ \text { Agreement calculated In a diferent way, l.e., number of months for which the women's } \\ \text { OC history agreed with her prescriber's, divided by the total number of months of OC } \\ \text { use recalled by the woman. This method may easily lead to artificially high agreement. } \\ \text { Estimated by Rosenberg et al. from a scattergram presented by Glass et al. }\end{array}$

to overestimate their $O C$ use even more than cases. A limitation in our design, and also in Stolley's, is that the control group differs from the typical population-based control groups used in many casecontrol studies. However, it is not very likely that our controls had given more thought to their $O C$ use than a randomly selected population-based sample. For the hospital controls, who constituted $36 \%$ of our control group, a biopsy for benign breast disease had been performed 5 years or longer ago.

We did observe a case-control difference in agreement on brand names. Breast cancer patients showed higher agreement than controls, although the difference was not significant (74\% vs $65 \%$ ). A similar result was described by Rosenberg et al., but Stolley et al. did not observe casecontrol differences in agreement on brand name. 
Coulter et al. reported that the first pill (both name and commencement of use) was better remembered than any later pills (10). This finding may be attributed to the greater significance for a woman of her first OC and its frequent relation to well-remembered life events such as marrlage (10). We are not able to corroborate this result, although the first plll was certainly not remembered any less well than later pills. This is, in itself, rather remarkable when seen in the light of the long recall period in our study. With recall period adjusted for in a multivariate analysis, agreement on both brand name and starting date of the first $O C$ was even slightly higher than that for the latest $O C$. Therefore, the difference between Coulter's study and the one presented here may also be explained by a longer recall period in our study.

This study was also set up to test the feasibility of obtaining information on OC use from prescribers. Although prescriber collaboration was very high (94\%), usable OC information was only obtained for $46 \%$ of OC preparations mentloned by the women. Complete information was only obtained for $34 \%$ of all preparations. It can be concluded, therefore, that prescriber records cannot be used as the sole data source in a case-control study. However, we found prescriber records to be extremely useful for supplementing women's $O C$ histories, particularly regarding specific brand names and stopping dates connected to a change of contraceptive method (i.e. sterilization, insertion of intrauterine device and vasectomy). In the ongoing case-control study of breast cancer risk and $\mathrm{OC}$ use, it was, therefore, decided to collect information on OC use from both the women and their prescribers. Decision rules have been established to sort out, in case of conflicting information from user and prescriber, whose report of OC use will be considered to be most correct.

\section{Acknowledgements}

The authors wish to thank the Netherlands Cancer Institute's Cancer Registry (G. Went-Boerman) for assistance in patient selection, $\mathrm{H}$. van der Woord for assistance in computer programming, and $\mathrm{Dr}$ N.K. Aaronson for critical review of the manuscript.

\section{References}

1. Gordis $L$. Assuring the quality of questionnaire data in epidemiologic research. Am $J$ Epidemiol 1979; 109: 21-24.

2. Harlow SD, Linet MS. Agreement between questionnaire data and medical records: The evidence for accuracy of recall. Am J Epidemiol 1989; 129: 233-248.

3. UK National Case-control Study Group. Oral contraceptwe use and breast cancer risk in young women. Lancet 1989; i: 973-982.

4. Skegg DCG. Potential bias in case-control studies of oral contraceptives and breast cancer. Am J Epidemiol 1988; 127: 205-211.

5. Copeland KT, Checkoway H, McMichael AJ, et al. Bias due to misclassification in the estimation of relative risk. Am J Epidemiol 1977, 105: 488-495.

6. Marshall JR, Priore R, Graham S, Brasure J. On the distortion of risk estimates in multiple exposure level case-control studies. Am J Epidemiol 1981; 113: 464-473.

7. Glass $R_{1}$ Johnson $B$, Vessey M. Accuracy of recall of historles of oral contraceptive use. $\mathrm{Br} J \mathrm{Prev}$ Soc Med 1974; 28: 273-275.

8. Stolley PD, Tonascia JA, Sartwell PE, et al. Agreement rates between oral contraceptive users and prescribers in relation to drug use histories. Am J Epidemiol 1978; 107: 226-235.

9. Rosenberg MJ, Layde PM, Ory HW, et al. Agreement between women's histories of oral contraceptive use and physician records. Int J Epidemiod 1983; 12: 84-87.

10. Coulter $A$, Vessey $M$, McPherson $K$. The ability of women to recall their oral contraceptive histories. Contraception 1986; 33: 127-137. 